Gynäkologische Endokrinologie 2012 · 10:120 DOI 10.1007/s10304-012-0492-8

Online publiziert: 5. April 2012

(c) Springer-Verlag 2012

M. Goeckenjan · T. Rabe · T. Strowitzki Abteilung für Gynäkologische

Endokrinologie und Fertilitätsstörungen,

Universitätsfrauenklinik Heidelberg, Heidelberg

\title{
Erratum zu: Postkoitale
} Kontrazeption

\section{Gynäkologische}

Endokrinologie (2012)

$10: 45-56$

http://dx.doi.org/10.1007/

s10304-011-0463-5

In der deutschen Zusammenfassung, im englischen Abstract und in Tab. 4 des o. g. Beitrags ist die Angabe zur Dosierung von Ulipristalacetat falsch: Statt $3 \mathrm{mg}$ muss es $30 \mathrm{mg}$ heißen.

Der Verlag bittet, den Fehler zu entschuldigen.

Die Redaktion

\section{Korrespondenzadresse}

M. Goeckenjan

Abteilung für Gynäkologische Endokrinologie und Fertilitätsstörungen, Universitätsfrauen-

klinik Heidelberg

Voßstr. 9, 69115 Heidelberg

maren.goeckenjan@med.uni-heidelberg.de 